teachers ; but while calling for concrete Government plans in this field, the Federation's memorandum gives little indication of concrete support from industry in the release of staff for part-time teaching. The Federation regards the day-release system as a valuable method of providing further training for potential technicians and technologists, and urges its member firms to increase the volume of day-release for this purpose. It agrees that many women could be trained in technological subjects, and holds that industry provides ready openings for women who are technically qualified on appointment. The adoption of 'sandwich' courses by more firms is urged, and such courses are discussed in some detail, particularly in regard to the importance of background information, co-operation between technical colleges and firms, amenities, finance, and the relevance of the proposals of the National Council for Technological Awards.

\section{International Council of Museums: Conference in Switzerland}

THE fourth general conference of the International Council of Museums was held in Switzerland during July 2-9 under the presidency of Dr. George A. Salles, director of the French museums. Some 250 delegates from more than thirty countries attended, including at least four from Great Britain. The conference was held in Basle, Zurich and Geneva, and French and English were used as the working languages. Working gioups dealing with specified subjects replaced the usual lectures and discussions. Dealing mainly with display and museum technique, this arrangement was eminently satisfactory and stimulating to those who took part. This was especially the case where broad principles of museology were discussed rather than when a particular exhibit or room was the subject for the working group. A series of five public lectures was delivered under the central theme of "The Museum in our Time". These were given by Dr. George Salles, Sir Gavin de Beer, Dr. Bengt Thordeman, Dr. Karl Bassler and Mr. Francis Taylor. The programme of lectures and working groups was liberally interspersed with visits to museums and to art galleries and receptions with very generous hospitality. The International Campaign for Museums, to be held in the week commencing October 8 next, was formally proclaimed by M. André Leveille, director of the Palais de la Découverte, Paris, and it was decided to hold the next conference in 1959 in the Scandinavian countries with headquarters in Stockholm.

\section{Products of Starch Hydrolysis}

Messrs. Vittorio, Krotkov, Nelson and Bidwell have examined the products of starch hydrolysis and their metabolism, using tobacco leaves in which the starch content is very high after photosynthesis (Canad. J. Bot., 34, No. 2, 209; 1956). Carbon-14 labelled tobacco leaf starch, digested with $N$ sulphuric acid in a boiling water bath, was not completely hydrolysed to glucose even after $24 \mathrm{hr}$. After three hours hydrolysis, paper paitition chromatography with butanol-ethanol-water solvent revealed that besides glucose there were four carbon-14 labelled products with $R_{F}$ values lower than glucose. When these bands were fed individually to tobacco leaves in light, they were incorporated into sucrose, glucose, fructose and starch, and were better starch formers than glucose, glucose-1-phosphate or maltose.

\section{Tropical Tuna Resources of the Eastern Pacific}

THE tropical tunas which inhabit the high seas off the shores of the Americas from California to Peru and northern Chile suppor's the most valuable fishery of the eastern Pacific Ocean. This consists of populations of two species, the yellow-fin tuna, Thunnus (Neothunnus) macropterus, and the skipjack (barrelete), Katsuwonus pelamis. In 1953, 140 million pounds of yellow-fin and 134 million pounds of skipjack were produced from the eastern Pacific. The preponderant share of the catch is taken by fishing vessels based on the west coast of the United States-very modern, long-range craft forming one of the most specialized fishing fleets in the world. A small but appreciable share of the catch is taken by vessels based in Peru. Most of the landings in countries other than the United States are transhipped frozen to the United States for processing as canned tuna. A scientific investigation of the tuna resources of this important fishery has been under. taken by the Inter-American Tropical Tuna Commission. A description of its work was given by its director, Milner B. Schaefer, at the United Nations conference in Rome during April 18-May 10, 1955, dealing with the Conservation of the Living Resources of the Sea.

\section{Effects of Radiation on Dielectric Materials}

A CONFERENCE on "The Effects of Radiation on Dielectric Materials" was held at the United States Naval Research Laboratory, Washington, D.C., during December 14-15, 1954, under the joint auspices of the Naval Research Laboratory and the Office of Scientific Research of the Air Research and Development Command, and the report of the proceedings has recently been published (No. PB111863; pp. 169; Washington, D.C.: Office of Technical Services, Department of Commerce, $1956 ; 4.25$ dollars). The object of the conference was to provide an exchange of information on the research programmes and progress of the various laboratories engaged in the study of the effects of radiation, and als. to examine and discuss the general acpects of the wide variety of disciplines involved in this field of investigation. Representatives of many United States government laboratories and of university and industrial laboratories participated in the conference, and survey talks on various aspects of radiation effects were delivered by Drs. M. Burton (Notre Dame University), R. Smoluchowski (Carnegie Institute of Technology), K. H. Sun (Westinghouse Electric Corporation) and D. Billington (Oak Ridge National Laboratory). The article by Dr. Sun, entitled "Effects of Atomic Radiation on High Polymers", is particularly valuable because of its extensive bibliography, compiled by F. A. Pecjak and the author, which consists of 217 references. The proceedings consisted of four sessions, and twenty-one papers were presented. They include, in addition to the survey talks, a description of research and radiation effects in insulating materials carried out at the Brookhaven National Laboratory ; "Radiation Effects on Glass", by N. J. Kreidl (Bausch and Lomb Optical Co.); and several discussions of the effects of atomic radiation on polymers, including polyethylene and 'Teflon', at low temperatures, and of general radiation on crystals, including diamond.

\section{University of l.eeds: Gifts}

THE following gifts have been received by the University of Leeds : $£ 2,000$ from an anonymous 